SHORT REPORT

\title{
Trends in the uptake and delivery of smoking cessation services to smokers in Great Britain
}

\author{
John Britton, Sarah Lewis
}

J Epidemiol Community Health 2004;58:569-570. doi: 10.1136/jech.2003.015271

S moking kills more people than any other avoidable factor in the UK, and smoking cessation interventions are among the most cost effective treatments in medicine. ${ }^{1}$ Guidelines recommending routine implementation of smoking ascertainment and cessation in clinical practice were first published in the UK in $1998,{ }^{2}$ and in the same year the UK government allocated funding to establish specialist smoking cessation services throughout the National Health Service. ${ }^{3}$ Since 2001 the antismoking drug bupropion and all nicotine replacement therapy (NRT) products have been available on NHS prescription, and their use supported by the National Institute for Clinical Excellence. ${ }^{4}$ The strong message of these policy developments is that advising smokers to quit, and providing behavioural and therapeutic cessation support, should by now be a standard component of medical practice. The recent Omnibus survey of Great Britain $^{5}$ provides an opportunity to discover if this is indeed the case.

\section{PARTICIPANTS, METHODS, AND RESULTS}

The Omnibus survey is an annual survey of a probability sample of 6000 households in Great Britain, sampling one person at random from all aged 16 and over in each household. ${ }^{5}$ In 2002, data were collected from 3822 people, which after excluding sampled addresses that proved to be ineligible, represented a response of $70 \%{ }^{5}$ Since 1996, with the exception of 1998, the survey has asked all smokers whether within the past five years they had been given advice in giving up smoking from their general practitioner or other healthcare staff. Since 1999, smokers have also been asked whether, in the past year, they had asked their GP or other health professional for help with quitting, been referred to a smoking cessation service, or bought or been prescribed NRT or other cessation therapy.

The published data show that the proportion of smokers recalling receipt of advice on smoking from any health professional in the past five years has, if anything, fallen between 1996 and 2002, from $46 \%$ to $42 \%$ ( $\chi^{2}$ test for trend $\mathrm{p}=0.09)$. Within that trend there are fluctuations in the proportions recalling input from different categories of medical staff, the slight downward trend in general practitioner contributions being offset by increased input from other general practice staff (fig lA). The proportion of current smokers seeking help or advice within the past year has also fallen, from $44 \%$ in 1999 to $36 \%$ in $2002(p<0.001)$, and the proportion receiving NRT or other pharmacotherapy from about $17 \%$ to $14 \%$ respectively ( $\chi^{2}$ for trend $p=0.09$, fig $1 \mathrm{~B}$ ). Although these figures all exclude data from smokers who gave up during these years, data available for 2002 indicate that the proportion of ex-smokers in the past year was small (7.6\%) and that inclusion of data from ex-smokers made very little difference to any of proportions reported.

\section{Key points}

- The proportion of smokers recalling receiving help or advice on smoking from any health professional has, if anything, fallen in the past five years, despite the policy initiatives implemented in 1998 to make smoking cessation a priority in clinical practice.
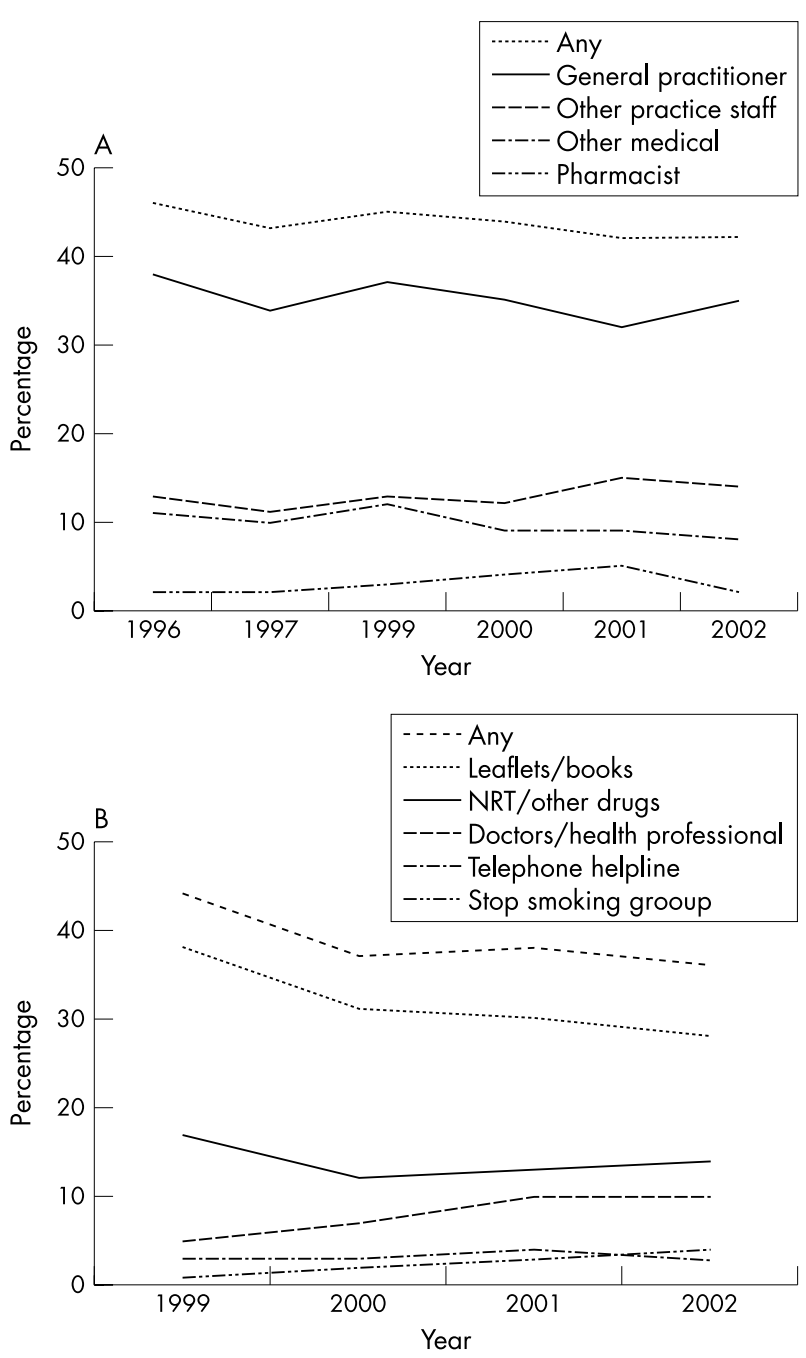

Figure 1 (A) Sources of advice on smoking cessation in the past five years recalled by smokers 1996-2002 (no data for 1998). (B) Sources of help used in the past year by current smokers 1999-2002. 


\section{Policy implications}

- Healthcare professionals need to implement cessation interventions as a routine and systematic component of their work.

\section{COMMENT}

These trends suggest that national policy initiatives to make smoking cessation a priority have not resulted in any clear increase in the proportion of smokers receiving advice or pharmacotherapy. This study is a secondary analysis of published data so we are not able to adjust for differences in age structure in the population during the study, but the prevalence of smoking in adults in the UK has been comparatively stable during the study period so it is unlikely that this will have appreciably biased our results. Although the measures of uptake of advice and help are in some cases based on recall of approaches initiated by the smoker rather than by health professionals, the figures for pharmacotherapy relate to a treatment initiated by either the smoker or by health professionals. The clear implication of the trends is that cessation services are still being taken up by a small and comparatively static proportion of smokers. It is important that ascertainment of smoking status, provision of advice to stop smoking, and delivery of effective behavioural and pharmacological support to motivate smokers now becomes a routine component of clinical practice.

\section{ACKNOWLEDGEMENTS}

We would like to thank Howard Meltzer and Deborah Lader for providing additional data from the Omnibus survey for this work.

\section{Authors' affiliations}

J Britton, Division of Epidemiology and Public Health, University of Nottingham, City Hospital, Nottingham, UK

S Lewis, Division of Respiratory Medicine, University of Nottingham, City Hospital

Funding: none.

Competing interests: none declared.

Correspondence to: Professor J Britton, Division of Epidemiology and Public Health, University of Nottingham, Clinical Sciences Building, City Hospital, Nottingham NG5 1PB, UK; j.britton@virgin.net

Accepted for publication 17 November 2003

\section{REFERENCES}

1 Parrott S, Godfrey C, Raw M, et al. Guidance for commissioners on the costeffectiveness of smoking cessation interventions. Thorax 1998;53(suppl 5 , part 2):S1-38.

2 Raw M, McNeill A, West RJ. Smoking cessation guidelines for health care professionals. Thorax 1998;53(suppl 5, part 1):S1-19.

3 Department of Health. Smoking kills. A white paper on tobacco. London: The Stationery Office, 1998.

4 National Institute for Clinical Excellence. Guidance on the use of nicotine replacement therapy (NRT) and bupropion for smoking cessation. London: National Institute for Clinical Excellence, 2002.

5 Lader D, Meltzer H. Smoking related behaviour and attitudes, 2002. London: Office for National Statistics, 2003 (http://www.statistics.gov.uk/ downloads/theme_health/Smoking_Related_2002.pdf)

\section{$\mathrm{ECHO}$}

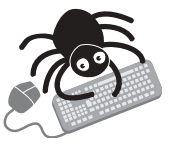

Please visit the Journal of Epidemiology and

Community Health website [www.jech. com] for a link to the full text of this article.
A community level syphilis prevention programme: outcome data from a controlled trial

M W Ross, N S Chatteriee, L Leonard

Objectives: This study investigated the impact of a small media campaign to reduce syphilis through testing, treatment, and condom use in two urban predominantly African-American communities with high syphilis rates.

Methods: Data were collected from intervention and comparison zip codes using cross sectional street intercept interviews at baseline and 2 years later $(n=1630)$ following a small media syphilis prevention campaign with role model story posters, billboards, and other merchandise. Community businesses and a community based organisation served as partners, distributing condoms and small media.

Results: Comparing intervention with comparison zip codes, there were significant increases in condom use in last sexual act, and some aspects of knowledge of syphilis. However, there was significant cross contamination of media impact, with respondents in the comparison zip code seeing an average of two media items compared with three in the intervention zip code. Media exposure was associated with significant increases in knowledge of syphilis, testing, and condom use.

Conclusions: Targeted community based small media interventions using community partners for distribution are effective in increasing syphilis knowledge, testing, and condom use.

A Sexually Transmitted Infections 2004;80:100-104. 